\title{
OS ESCRITOS DE CAROLINA MARIA DE JESUS: DETERMINAÇÕES E IMAGINÁRIO
}

\author{
Marília Novais da Mata Machado \\ Faculdade Novos Horizontes
}

RESUMO: O artigo relata uma pesquisa no domínio social histórico, aqui definido segundo duas dimensões, uma determinista e outra imaginária. A noção de formação discursiva e alguns procedimentos de análise de discurso são utilizados na investigação das condições de produção dos escritos de Carolina Maria de Jesus. São apontadas as determinações sociais, geográficas, linguísticas e históricas que atuaram na escrita e na recepção da obra da autora. Aponta-se também a operação do indeterminado, do aleatório e do imaginário, ingredientes importantes na criação e na revelação dos escritos. Sempre considerando o domínio social histórico, analisa-se a aceitação da autora e de sua obra.

PALAVRAS-CHAVE: domínio social histórico; formação discursiva; determinismo; imaginário social; Carolina Maria de Jesus.

\section{THE WRITINGS OF CAROLINA MARIA DE JESUS: DETERMINATIONS AND IMAGINARY}

ABSTRACT: The article reports a research work in the social historical domain, here defined according to two dimensions - a deterministic one and an imaginary one. The notion of discursive formation and some procedures of discourse analysis are used in the investigation of the conditions within which the writings of Carolina Maria de Jesus were produced. Social, geographical, linguistic, and historical determinations operating in the work and in the reception of her writings are pointed out. The operation of undetermined, random, and imaginary events - important ingredients in the creation and revelation of those writings - are also revealed. Still considering the social historical domain, the author's popularity and her written work are analyzed.

KEYWORDS: social historical domain; discursive formation; determinism; social imaginary; Carolina Maria de Jesus.

O domínio social histórico, noção tomada de empréstimo a Castoriadis (1982, 1987, 1999), compreende duas dimensões apreendidas simultaneamente: a determinista, que dá conta de continuidades, permanências e estruturas mais ou menos constantes da sociedade, demandando uma abordagem principalmente sincrônica; a imaginária, que dá conta das transformações, da autopoiesis ou criação social, requerendo perspectiva mais diacrônica.

O pensamento herdado possui os dispositivos teóricos e metodológicos para a apreensão da dimensão determinista, mas praticamente ignora a imaginária.

Uma metodologia capaz de captar o domínio social histórico caminha entre os pólos sincronia/diacronia, estruturalismo/funcionalismo, ordem/desordem, determinações/significações imaginárias sociais, tomando-os como coexistentes e evitando vê-los como opostos que se excluem reciprocamente. Busca "captar simultaneamente o acidente, contingente e efêmero (...) e a estrutura, mais ou menos permanente, contínua e determinada" (Machado, 2005, p.60).

A análise aqui proposta da produção e repercussão dos escritos de Carolina Maria de Jesus pretende mostrar a atuação das duas dimensões e o dispositivo metodológico usado para apreender o domínio social histórico em foco.

O caso Carolina Maria de Jesus é um bom exemplo da atuação de fortes determinações e, também, da operação do indeterminado e conseqüente surgimento de novo imaginário. Seus próprios escritos nos chegaram quase por acidente. Além disso, às vezes deliberadamente, outras por suas próprias determinações, a autora violou os códigos que sustentavam a imobilidade, perenidade e reprodução da desigualdade social no país, criando, assim, outras significações imaginárias sociais.

Carolina sofreu os efeitos do rompimento com a continuidade. Não por acaso a chamaram de difícil, insubmissa, petulante, geniosa, atrevida, rebelde, transgressora, ousada, explosiva, agressiva, arrogante, desafiadora e, mais tarde, com seu sucesso em declínio, de fracassada, vítima e louca. Mas chamaram-na também de terna, alegre e corajosa.

\section{Procedimentos de Pesquisa}

A pesquisa partiu da leitura atenta da obra da escritora, das notícias de jornais de sua época, críticas literárias, artigos e teses sobre ela; além disso, foram feitas entrevistas com pessoas que a conheceram.

Com a ajuda da noção foucaultiana de formação discursiva, buscou-se a dimensão determinista nas "regras anônimas, históricas, determinadas" (Foucault, 1987, p.136) atuantes, primeiro, nos anos 1940 e 50 no Brasil em industrialização, que definiram as condições de produção dos textos de Carolina; depois, as atuantes no início dos anos 1960, que favoreceram o sucesso, no Brasil, de 
apenas um dos livros da autora; finalmente, as regras que reduziram Carolina ao silêncio, no restante dos anos 1960 e nos 70, e as que levaram à sua redescoberta a partir da década seguinte.

A dimensão imaginária foi buscada no impacto dos escritos de Carolina sobre a sociedade e na compreensão do universo da autora, encerrado em preconceitos (contra nordestinos, sírios, favelados), em dicotomias (brancos e pretos; ricos e pobres; trabalhadores e malandros; cidade e favela) e em conservadorismos (políticos, sociais, morais), dos quais ela se libertou parcialmente ao escrever.

Recursos de análise do discurso foram aplicados na leitura e interpretação tanto da obra da escritora, quanto de reportagens, transcrições de entrevistas e artigos lidos. Análise do discurso é definida aqui como uma leitura atenta, que leva em consideração aspectos lingüísticos dos textos e aspectos psicológicos e sociológicos das condições em que foram produzidos, além da articulação entre os textos e seus lugares de produção. Tal definição fundamenta-se em Machado (2005), que propõe a pesquisa do domínio social histórico à luz das teorizações de Pêcheux (1990), sobretudo sua ênfase nas condições de produção do discurso, e das de Foucault que, acompanhando Passos (2004, p.42), utiliza "uma análise textual (de vocabulário, gramática, coesão e estrutura textual) aliada à análise discursiva propriamente dita: a força dos enunciados (...); a coerência dos textos; a intertextualidade".

\section{Resultados e Discussões}

\section{As determinações}

Veja-se um pouco da história de Carolina Maria de Jesus. Seu livro Quarto de despejo foi lançado pela Livraria Francisco Alves em agosto de 1960 e editado oito vezes no mesmo ano. Em menos de 12 meses, mais de 70 mil exemplares foram vendidos. Uma tiragem bem-sucedida, na época, era de cerca de quatro mil exemplares. Nenhum autor no Brasil chegara perto desse sucesso de venda.

Revistas internacionais do porte de Life, Paris Match, Time e Época fizeram reportagens sobre Carolina e o seu livro.

Nos cinco anos subsequientes, Quarto de despejo foi traduzido para 14 idiomas e alcançou mais de 40 países, começando pela Dinamarca, Holanda, Argentina, França, Alemanha, Suécia, Itália, passando pela Tchecoslováquia, Romênia, Inglaterra, Estados Unidos e chegando à Rússia, Japão, Polônia, Hungria e Cuba (Perpétua, 2000).

O sucesso é inexplicável, quando se sabe que a autora era uma favelada de quarenta e poucos anos, tinha estudado apenas até a segunda série do curso primário, numa cidade pequena do interior de Minas Gerais, fora lavradora, migrara para São Paulo, tentara a profissão de empregada doméstica, vivia de catar papel, ferros e estopa no lixo, era negra retinta, descendente de escravos, solteira, mãe de três filhos pequenos. Na época, mais do que hoje, a literatura era ofício de homens brancos, letrados e, com raras exceções, ricos e em posição social elevada (Lajolo, 1995), pois escrever era, como hoje, atividade pouco rendosa.

Sucesso mais inexplicável ainda, porque o livro espelhava precisamente as determinações de raça, classe social, escolarização, profissão, procedência, sexo e idade da autora. Era o diário da fome cotidiana, da miséria, dos abusos e preconceitos sofridos por ela, seus filhos e outros favelados. A escrita era caótica, cheia de incorreções ortográficas, sintáticas e de pontuação.

\section{As significações imaginárias sociais versus determinações}

Carolina escrevia há cerca de 15 anos, na tentativa imaginária de escapar das dificuldades diárias e de afastar o nervosismo que a tomava quando a fome era intensa:

"Enquanto escrevo vou pensando que resido num castelo cor de ouro que reluz na luz do sol. Que as janelas são de prata e as luzes de brilhantes. Que a minha vista circula no jardim e eu contemplo as flores de todas as qualidades" (Jesus, 1993, p.52).

Carolina achava que o que fazia de melhor eram os poemas. Não dava valor algum ao diário. Era, ainda, autora de contos, romances, provérbios, pensamentos, peças teatrais, memórias e letras de música. Já tentara inúmeras vezes publicar seus manuscritos. Buscara redações de jornais e editoras; procurara intermediações de vizinhos no bairro rico; apresentara seus escritos ao pessoal do serviço social.

Contudo, num relance, todos viam de imediato, nos cadernos ensebados, catados no lixo, múltiplas determinações negativas para o ofício de escritora a que se propunha.

Mas, no início de 1958, aconteceu o encontro de Carolina com o jovem repórter alagoano da Folha da Noite, Audálio Dantas, que fora à favela do Canindé, onde ela morava, para fazer uma matéria e teve acesso aos cadernos. O diário de 1955, depoimento de poucas páginas do dia-a-dia na favela, chamou-lhe imediatamente a atenção. ${ }^{1}$

Dantas, diferentemente de Carolina, nadava na corrente do imaginário criador de sua época, o que em muito determinou suas ações: participava dos movimentos sociais e políticos daqueles anos, acompanhava a efervescência renovadora na música, no cinema, no teatro, na literatura, preocupava-se com as transformações sociais e com a coletividade, participava especialmente da criação do novo jornalismo, no qual reportagens com uma visão mais à esquerda e imbuídas de responsabilidade social passaram a ter espaço. Ele fez a primeira e bemsucedida matéria sobre Carolina, que consistiu na apresentação da escritora, incluindo fotos, uma poesia e citações do diário, tudo exposto como depoimento e denúncia da situação vivida pelos pobres, a partir da perspectiva interna da favela. 
Ao mesmo tempo, pediu a Carolina que retomasse o diário, o que ela fez de pronto. A primeira edição de Quarto de despejo (Jesus, 1960) traz 16 páginas relativas ao ano de 1955; as outras 153, além das ilustrações, cobrem de maio de 1958 a primeiro de janeiro de 1960 . Foram escritas depois do encontro de Carolina e Audálio. Escritas para ele. O jornalista também trabalhou arduamente sobre os manuscritos que ia recebendo. Respeitando a escrita original, fez, entretanto, com sensibilidade, muita seleção de textos e pequenas correções.

\section{Os escritos de Carolina}

A avaliação feita por Audálio Dantas dos escritos de Carolina perdura, de certa forma, até hoje: os diários são o que há de mais valioso, a poesia é composta de rimas pobres e quadrinhas ingênuas; talvez fosse possível aproveitar alguns contos (Dantas, 1958).

Com efeito, os escritos são antiquados: a matriz da maioria das poesias é Casimiro de Abreu (1839-1860) e dos romances e contos, Bernardo Guimarães (1825-1884), pois foram esses autores que Carolina teve oportunidade de ler. Os provérbios e pensamentos encontram paralelo na literatura gnômica medieval (Arrington, 1993). Como a maior parte dos manuscritos permanece inédita, outras avaliações, no mínimo, deveriam ser feitas: qual é o seu valor real como literatura e/ou depoimento de época e lugar?

\section{A atuação do indeterminado e o surgimento de novas significações sociais imaginárias}

Mas o que importa aqui é acentuar que ocorreram o improvável, o indeterminado e o inesperado. Houve o sucesso nacional e internacional de Quarto de despejo e suas conseqüências, de diferentes ordens, sobre o imaginário social: a instituição de movimentos em prol do desfavelamento, o incremento do fluxo da literatura produzida por mulheres, o incentivo a sonhos e projetos de ascensão social pela escrita, o receio de uma deturpação literária, já que, aparentemente, qualquer um podia escrever, críticas acirradas à divulgação no exterior do que havia de pior no Brasil. Quarto de despejo colocou em questão a visão romântica de favela então prevalecente, cujo paradigma era a letra da música Chão de estrelas, de Sílvio Caldas e Orestes Barbosa:

\footnotetext{
Meu barraco lá no morro do Salgueiro

Tinha o cantar alegre de um viveiro

(...)

A porta do barraco era sem trinco

Mas a lua, furando o nosso zinco

Salpicava de estrelas o nosso chão

E tu pisavas nos astros distraída
}

Descoberta no imaginário de uma época, Carolina deflagrou, com seu diário da fome e seu sucesso, outro imaginário social, provocando mudanças definitivas que, entretanto, permaneceram recalcadas por anos.
Pouca gente na época percebeu a singularidade do caso Carolina Maria de Jesus.

Muitos a badalaram, outros a ridicularizaram e houve os que acharam (e ainda acham) que Audálio Dantas foi seu ghost writer, que a escritora negra jamais existiu.

No entanto, o seu projeto, como o de muitos outros pobres, era bem simples: ter certo conforto, atravessar, se possível, barreiras de classe, o que se confirma no registro de 20 de julho de 1955 :

O meu sonho era andar bem limpinha, usar roupas de alto preço, residir numa casa confortável, mas não é possível. Eu não estou descontente com a profissão que exerço. Já habituei-me andar suja. Já faz oito anos que cato papel. $\mathrm{O}$ desgosto que tenho é residir em favela (Jesus, 1993, p.19).

\section{A (não) aceitação de Carolina e de sua obra}

O sucesso de Quarto de despejo subiu à cabeça de Carolina. Ela ficou deslumbrada, mas também apreensiva. Sentiu-se usada, como uma Cinderela negra que perderia o encanto, um pedaço de ferro cujo banho de ouro um dia esmaeceria, um pedaço de doce levado pelas formigas.

Foi assediada por numerosas pessoas que nunca havia visto e que lhe pediam dinheiro, um trator ou uma máquina de costura. Foi generosa com muita gente. Pagou passagem de avião para uma retirante que encontrara por acaso num aeroporto, sapato para um garoto pobre que viu na rua. Deu teto a desabrigados, comprou roupa e adornos para a família. Realizou o sonho da casa própria. Expôsse muito e, por isso, foi consumida e descartada.

$\mathrm{O}$ fim de seu sucesso no Brasil confundiu-se com o fim do período populista, antes do golpe militar de 64. No exterior, seus livros continuaram a ser lidos regularmente.

Carolina ainda publicou, em 1961, Casa de alvenaria (Jesus, 1961), livro também compilado por Audálio Dantas, mas pouco vendido, com uma única edição de 3000 exemplares. É, entretanto, um livro importante. Cobre os diários desde o dia da assinatura do contrato com a editora para a publicação de Quarto de despejo, a saída da favela, a compra da casa num bairro de classe média, a ambivalência da autora em relação à casa, os deslumbres e as angústias na nova posição. Talvez seja o único depoimento existente do cotidiano de uma ascensão social.

Por conta própria, depois que o sucesso arrefeceu, ela publicou oromance Pedaços da fome (Jesus, 1963)e, mais tarde, Provérbios (Jesus, s/d), livros que também não decolaram.

Soube sair de cena no final de 1963, bastante empobrecida, mas tendo comprado um pequeno pedaço de terra, em Parelheiros, ao sul de São Paulo, onde iniciaria a construção de uma casa. Plantava aí sua horta e criava galinhas. Passou por inúmeras dificuldades. Por volta de 1966, teve de vender a casa de alvenaria em São Paulo. 
Entretanto, os filhos continuaram os estudos, a família já não passava fome como no tempo da favela e ela conseguiu terminar a construção da casa de Parelheiros. Sua retirada de cena deu-se num momento adequado, pois São Paulo logo passou por reformas urbanísticas, o preço dos terrenos subiu muito, a questão da moradia agravou-se e o número de favelados aumentou. Se não tinha uma mesa farta e variada, como gostaria, ainda era possível, com os recursos do terreno conservado, comer, até enjoar, frango com couve. ${ }^{2}$

Boa parte da mídia não apreciou a retirada de Carolina. Já não podiam atirar pedras na sua Geni. Se antes da mudança já invadiam sua privacidade ("Carolina vai casar mesmo com o professor chileno!" - Última hora, 9/3/62) e a achincalhavam, depois, perdido o contato, sem entendê-la, ainda tentaram rebaixá-la, como nas manchetes:

Carolina de Jesus deixou a casa de alvenaria e voltou a catar papel em São Paulo (Jornal do Brasil, 1966);

Carolina de Jesus quer viver com os indígenas (Folha de S. Paulo, 5/2/1970);

Após a glória, solidão e felicidade (Folha de S. Paulo, 29/6/75);

Carolina: vítima ou louca? (Folha de S. Paulo, 1/12/76).

Ela continuou a escrever. A duas jornalistas vindas da França que a entrevistaram, em 1975, Carolina entregou um manuscrito, livro de reminiscências da infância e da adolescência, que, traduzido para o francês com o nome de Journal de Bitita (Jesus, 1982), foi publicado primeiro naquele país e quatro anos depois vertido para o português com o título de Diário de Bitita (Jesus, 1986).

Quando Carolina morreu, em 1977, os jornais ainda pareciam injuriá-la, relembrando mais os seus fracassos do que os sucessos, reduzindo sua obra a Quarto de despejo, embora uma leitura cuidadosa das notícias faça supor que os repórteres se perguntavam quem afinal fora aquela mulher. Novamente algumas manchetes:

Carolina Maria de Jesus: morreu a escritora favelada que escrevia para acabar com as favelas (Jornal do Brasil, 14/2/77);

Morre Carolina, a escritora da favela (Notícias populares, 14/2/77);

Carolina Maria de Jesus: a morte longe da casa de alvenaria (Jornal do Brasil, 14/2/77);

O triste epílogo: Carolina de Jesus (Diário da Noite, 15/2/77);

O fim de Carolina, pobre e já no esquecimento $(\mathrm{O}$ Estado de S. Paulo, 15/2/77);

Um enterro pobre para a escritora da favela (Notícias populares, 15/2/77);

Carolina Maria de Jesus - o ponto final da escritora favelada (Revista Fatos e Fotos, 28/2/77).

\section{Novas determinações e novos imaginários}

Mas a morte não foi o ponto final da escritora. Talvez o sinal, que poucos perceberam, dada a distância geográfica, tenha sido o lançamento na França, em 1982, do Diário de Bitita.

No ano seguinte, a Rede Globo de Televisão preparou o "Caso Verdade: de catadora de papéis a escritora famosa". Como se vê, discursivamente, o tratamento dado a Carolina foi outro. No mesmo ano, a Livraria Francisco Alves lançou a décima edição de Quarto de despejo e Carlos Vogt publicou excelente texto sobre Carolina: Trabalho, pobreza e trabalho intelectual, onde escreveu: "Ao transformar a experiência real da miséria na experiência lingüística do diário, [a autora] acaba por se distinguir de si mesma e por apresentar a escritura como uma forma de experimentação social nova" (Vogt, 1983).

Os tempos eram outros. Terminavam os sombrios anos da ditadura militar que sufocava o país desde 1964 e, mais do que nunca, o Brasil era tomado por movimentos participativos e associativos. Dois deles - o feminista e o negro - tomaram Carolina como um dos seus baluartes e reconheceram-na como pioneira. Com seu "corajoso pioneirismo", ela ainda "vai representar o imprevisto e o indomável”, escreveu Lajolo (1995, p.18).

Nos anos 90, dois professores universitários ajudaram a redescobrir a autora: o historiador paulista José Carlos Sebe Bom Meihy e o cientista social norte-americano Robert M. Levine, que há muitos anos utilizava os escritos de Carolina em suas aulas. Ambos incluíram, no livro que fizeram juntos sobre ela (Cinderela negra), dois textos seus inéditos (Jesus, 1994, 1994b) e apontaram o quanto ela tinha de singular:

Ser negra num mundo dominado por brancos, ser mulher num espaço regido por homens, não conseguir fixar-se como pessoa de posses num território em que administrar o dinheiro é mais difícil do que ganhálo, publicar livros num ambiente intelectual de modelo refinado, tudo isto reunido fez da experiência de Carolina um turbilhão (Meihy \& Levine, 1994, p.63).

Nos seus anos de Parelheiros, a autora preparara cópias idênticas de extratos dos originais, talvez numa tentativa de editoração semelhante à de Audálio Dantas para Quarto de despejo e Casa de alvenaria. Com esse material, foi possível a Meihy e Levine publicarem, também, Meu estranho diário (Jesus, 1996) e Antologia pessoal (Jesus, 1996b), já organizados previamente pela autora.

Esses dois livros surgiram quando Carolina já vinha sendo homenageada no exterior e no Brasil. Quarto de despejo foi reeditado em Cuba (1989), na Alemanha (1983, 1993) e no Brasil (1993). Casa de alvenaria na França $(1982,1984)$ e nos Estados Unidos (1997, 1998). Diário de Bitita foi traduzido na Espanha (1985).

A publicação de Meu estranho diário e de Antologia pessoal gerou polêmicas sobre a obra de Carolina Maria 
de Jesus, entre as quais a de maior repercussão foi a lançada por Marilene Felinto (1996), articulista da Folha de S. Paulo, que escreveu "Academia tenta, mas não consegue dar estatuto literário a Carolina de Jesus", com a réplica do antropólogo Roberto DaMatta (1996): "Literatura, como diz o bom senso, é o que as pessoas escrevem".

Graças também a Levine e Meihy, muitos manuscritos de Carolina foram microfilmados (1996) e estão disponíveis na Biblioteca Nacional, Rio de Janeiro.

Teses de doutorado a tomaram como tema (Magnabosco, 2002; Perpétua, 2000; Sousa, 2004) e muitos estudos sobre sua obra foram publicados, especialmente nos Estados Unidos (Arrington, 1993, 1993b; Castro-Klarén, Molloy, \& Sarlo, 1991; Levine, 1994; Levine \& Meihy, 1995; M.K., 1987; Platt, 1992).

A Câmara Municipal de Sacramento, cidade natal da escritora, outorgou-lhe o título de cidadã honorária (2001). Quarto de despejo foi selecionado para o vestibular da UFMG, em 2001, e da UnB, em 2004, gerando resenhas e críticas (Bylaardt, 2000; Cerchi, 2000; Simões, 2000). O nome de Carolina Maria de Jesus foi dado a ruas, creches, abrigos, associações, bibliotecas. O cineasta Jeferson De, da Trama Filme, realizou documentário curtametragem com Zezé Motta no papel da escritora (2003).

\section{Considerações Finais}

Carolina Maria de Jesus foi portadora de novo imaginário social e de transformações sociais que não se esgotaram. Há ainda que se ler todos os seus escritos, decifrar sua bagagem, apropriar-se de sua contribuição e reconhecer que ela exerceu sua autonomia como poucos, alterando o "tecido imensamente complexo de significações que impregnam, orientam e dirigem toda a vida dessa [nossa] sociedade e de todos os indivíduos concretos que, corporalmente, a constituem" (Castoriadis, 1987, p.230).

A análise aqui realizada permitiu compreender melhor a grande aceitação de Quarto de despejo e o paradoxal abandono da autora no Brasil. Tudo se passou como se bastasse a aceitação de seu livro. Quanto a ela, melhor ignorá-la, esquecê-la, por ser insubmissa, desenvolta e à vontade demais num mundo que, supostamente, não lhe pertencia; preconceituosa e conservadora demais para a sua época.

Mudanças no imaginário social, ocorridas inclusive graças a ela, não mais lhe exigem coerência política e ideológica. Ela foi simplesmente uma brasileira negra, pobre, pouco alfabetizada que, contra todas as determinações sociais então vigentes, viu-se alçada às luzes da ribalta e, apesar de usada e abusada, saiu-se com grande dignidade.

\section{Notas}

1. Entrevista realizada com Audálio Dantas, a 29 de julho de 2005, para a pesquisa.
2. Entrevista realizada com Vera Eunice Jesus de Lima, filha da autora, a 30 de julho de 2005, para a pesquisa.

\section{Referências}

Arrington Jr., M.S. (1993). Gnomic literature from the favela: The Provérbios of Carolina Maria de Jesus. Romance Notes, 34(1), 79-85.

Arrington Jr., M.S. (1993b). From the garbage dump to the brick house: the diaries of Carolina Maria de Jesus. South Eastern Americanist, 36(4), 1-12.

Bylaardt, C. O. (2000, 4 de dezembro) Estudo de Obras Literárias. Vestibular 2001, UFMG. Quarto de Despejo. Carolina Maria de Jesus: O rebotalho. Estado de Minas.

Castoriadis, C. (1982). A instituição imaginária da sociedade (G. Reynaud, Trad.; L.R.S. Fortes, Rev. Técn.). Rio de Janeiro: Paz e Terra. (Original publicado em 1975)

Castoriadis, C. (1987) As encruzilhadas do labirinto / 2: Os domínios do homem. (J.O.A. Marques, Trad.; R. Janine. Ver. Técn.). Rio de Janeiro: Paz e Terra (Original publicado em 1986).

Castoriadis, C. (1999). Feito e a ser feito: As encruzilhadas do labirinto /V. (L. Valle, Trad). Rio de Janeiro: DP\&A.

Castro-Klarén, S.; Molloy, S. \& Sarlo, B. (1991). Women's writing in Latin America: an anthology. Boulder, San Francisco, Oxford: Westview Press.

Cerchi, C.A. (2000). Sacramentana é leitura selecionada para o vestibular 2001. Destaque In. Sacramento, dez., 6-9.

Da Matta, R. (1996, 11 de novembro). Carolina, Carolina, Carolina de Jesus. Jornal da Tarde.

Dantas, A. (1958). O drama da favela escrito por uma favelada: Carolina Maria de Jesus faz um retrato sem retoque do mundo sórdido em que vive. Folha da Noite. São Paulo, ano XXXVII, n. 10.885, 9 de maio.

Felinto, M. (1996, 29 de setembro). Clichês nascidos na favela. Caderno Mais. Folha de São Paulo.

Foucault, M. (1987). A arqueologia do saber (L. F. B. Neves, Trad). 3. ed. Rio de Janeiro: Forense-Universitária. (Original publicado em 1969).

Jesus, C. M. de. (1960). Quarto de despejo: diário de uma favelada. São Paulo: Livraria Francisco Alves (Editora Paulo de Azevedo Ltda).

Jesus, C. M. de. (1961). Casa de alvenaria: diário de uma exfavelada. São Paulo: Livraria Francisco Alves (Editora Paulo de Azevedo Ltda).

Jesus, C. M. de. (1963). Pedaços da fome. São Paulo: Editora Áquila Ltda.

Jesus, C. M. de. (s/data). Provérbios. São Paulo: s/editora.

Jesus, C. M. de. (1982). Journal de Bitita (R. Valbert, Trad.). Paris: A. M. Métailié.

Jesus, C. M. de. (1986). Diário de Bitita. Rio de Janeiro: Nova Fronteira.

Jesus, C. M. de. (1993). Quarto de despejo: diário de uma favelada. São Paulo: Editora Ática.

Jesus, C. M. de. (1994). Minha vida. Em J.C.S. Meihy \& R.M. Levine (Eds.), Cinderela Negra: a saga de Carolina Maria de Jesus (pp. 172-189). Rio de Janeiro: UFRJ.

Jesus, C. M. de. (1994b). O Sócrates africano. Em J.C.S. Meihy \& R.M. Levine (Eds.), Cinderela negra: a saga de Carolina Maria de Jesus (pp.190-196). Rio de Janeiro: UFRJ.

Jesus, C. M. de. (1996). Meu estranho diário. São Paulo: Xamã. 
Jesus, C. M. de (1996b). Antologia pessoal. Rio de Janeiro: Editora UFRJ.

Lajolo, M. (1995). A leitora no quarto dos fundos. Leitura: Teoria. 14(25), 10-18.

Levine, R. M. (1994) The cautionary tale of Carolina Maria de Jesus. Latin American Research Review, 29(10), 55-83.

Levine, R. M. \& Meihy, J. C. S. B. (1995). The life and death of Carolina Maria de Jesus. Albuquerque: University of New Mexico Press.

M. K. (1987). Inter-American notes. The Americas. A Quartely Review if the Inter-American Cultural History. 42(4), 483-485.

Machado, M. N. M. (2005). Uma metodologia para a pesquisa do domínio social histórico. Memorandum: Memória e História em Psicologia, 9, 57-64. (Acessado de http://www.fafich.ufmg.br/ $\sim$ memorandum/a09/machado01.htm)

Magnabosco, M. M. (2002). Reconstruindo imaginários femininos através dos testemunhos de Carolina Maria de Jesus: um estudo sobre gênero. Tese de doutorado não-publicada, Programa de Doutorado em Literatura Comparada, Faculdade de Letras da Universidade Federal de Minas Gerais. Belo Horizonte, MG.

Meihy, J. C. S. B \& Levine, R. M. (1994). Cinderela Negra: a saga de Carolina Maria de Jesus. Rio de Janeiro: UFRJ.

Passos, I. C. F. (2004). Razão e loucura: a querela entre Foucault e Derrida. Em I. F. Passos \& F. Belo (Eds.), Na companhia de Foucault: 20 anos de ausência (pp. 29-45). Belo Horizonte: Fale/UFMG

Pêcheux, M. (1990). Análise automática do discurso (AAD-1969). Em F. Gadet \& T. Hak (Ed.), Por uma análise automática do discurso: uma introdução à obra de Michel Pêcheux (pp. 61-161). (E. P. Orlandi, Trad.). Campinas: Editora Unicamp.

Perpétua, E. D. (2000). Traços de Carolina Maria de Jesus: gênese, tradução e recepção de Quarto de Despejo. Tese de doutorado não publicada, Programa de Doutorado em Literatura Comparada, Faculdade de Letras da Universidade Federal de Minas Gerais. Belo Horizonte, MG.

Platt, K. (1992). Race and gender representations in Clarice Lispector's "A menor mulher do mundo" and Carolina Maria de Jesus' “Quarto de Despejo”. Afro-Hispanic Review, 11(1-3), 51-57.

Simões, R. (2000). Quarto de despejo, quarto de desejos. Revista de Literatura (Vestibular UFMG. Bitarães Neto, A. (Ed), 2, 111-126.

Sousa, G. H. P. de. (2004). Carolina Maria de Jesus: o estranho diário da escritora vira-lata. Tese de doutorado não publicada. Programa de Doutorado em Teoria Literária, Instituto de Letras, Departamento de Teoria Literária e Literaturas/UnB. Brasília, DF.

Vogt, C. (1983). Trabalho, pobreza e trabalho intelectual. Em R. Schwarz (Ed.), Os pobres na literatura brasileira (pp.204-213). São Paulo: Brasiliense.

Marília Novais da Mata Machado é doutora pela Universidade de Paris Norte, Paris XIII (1990) e mestre pela Pontifícia Universidade Católica do Rio de Janeiro (1972). Foi professora da área de Psicologia Social na Faculdade de Filosofia e Ciências Humanas da Universidade Federal de Minas Gerais (1967-1993). Atualmente, leciona no Mestrado de Administração, Faculdade Novos Horizontes, Belo Horizonte, MG. Endereço para correspondência: Rua Professor Júlio Mourão, 17 apto 101, Belo Horizonte, MG, CEP 30380-340

marilianmm@terra.com.br

\section{Os escritos de Carolina Maria de Jesus: determinações e imaginário}

Marília Novais da Mata Machado

Recebido: 11/12/2005

$1^{\text {a }}$ revisão: 02/05/2006

Aceite final: 05/07/2006 